\title{
Substantiation of Optimal Design Parameters for New System Angle Headframes in State-of- the Art Mines
}

\author{
Elena Kassikhina ${ }^{1, *}$, Vladimir Pershin ${ }^{1}$, and Yunliang Tan $^{2}$ \\ ${ }^{1}$ T.F. Gorbachev Kuzbass State Technical University, 65000028 Str., Kemerovo, Russia \\ ${ }^{2}$ Shandong University of Science and Technology, Qingdao, China
}

\begin{abstract}
The article formulates a new concept for design of the steel angle headframes of the new system for state-of-the art mines. One of the important structural elements of the steel headframe is a rig, installed above mouth of the vertical shaft and designed for equipment and passage of mine conveyances in shaft. A traditional frame rig of rectangular section is the most cumbersome and heavy-weight part of the headframe due its load-bearing. The proposed by the author headframe of multifunctional purpose, that includes a non-load bearing rig of circular cross-section, will allow reducing load on mine mouth and forgoing the sub-frame that greatly simplifies the task of finding an optimal design solution for the structure. There is an analysis of the most significant factors that significantly affect formation of the main design parameters of the sheave wheels and the rig of the examined headframe. The proposed idea of the independently operating structural units, one of which is a circular rig, significantly reduces a number of controlled variables, with which a designer can vary designing a headframe.
\end{abstract}

\section{Introduction}

Headframe takes special place in the complex of mining facilities. First of all, headframe is an engineering structure designed to maintain pulleys of winder or the winder itself at a certain point. Secondly, in headframe the dumping of minerals lifted to the surface is carried out, so it needs to ensure the smooth operation of conveyances. For this purpose headframes are furnished with special guides: conductors and dumping curves. Thirdly, headframe structure acts as a continuation of a shaft; therefore, it is fully involved in the process of ventilation of underground workings and should be well sealed. Design of the headframe is classified as: angle headframe (A-shaped, four-post, tent) and tower-type [1-12]. Design of the steel angle headframe. Options of the constructive embodiment of steel angle headframes, their advantages and disadvantages in dealing with basic tasks.

\section{Materials and Methods}

Substantiation of optimal design parameters for angle headframes of the new system to meet given tasks:

\footnotetext{
* Corresponding author: kalena-07@mail.ru
} 
- formalize search for an optimal technical solution in lieu of alternate design in view of loads caused by: lifting, guides, compression and depression, provided that lining is sealed, - articulate a new concept of steel angle headframe design of the new technological level.

The assigned tasks are most fully solved in the steel angle four-post headframes of the rig system, which is confirmed by long practice of their design and operation both in our country and [1-12].

In headframes of this system (Fig. 1) rig 1 of the rectangular cross-section is a loadbearing part of headframe and together with jib 2 receives load from hoist and transfers it through base frame 3 on mine mouth 4 .

Angle headframe of the rig system installed in almost all mines of Kuzbass, indicating their undoubted advantages, but there are a number of disadvantages.

Design solutions of some units require revision, as they contribute to development of corrosion. Presence of a large number of braces in the rig frame contributes to accumulation of coal dust, slag and lube at the nodes of connection and, as a consequence, appearance of significant corrosion in stagnant places

Support rig unit on base frame requires special attention:

- base frame is located below zero level in the zone of high humidity, that leads to development of corrosion of its elements and rig supporting elements;

- base frame should be mounted into mine mouth, what complicates assembling process of the rig;

- base frame due to its size, restricts operating conditions and performance of reconstruction and shaft deepening.

Also, it is necessary to improve situation with the rig lining. The matter is that its rectangular configuration dictates application of standard wall panels as an external protection. It creates a large number of joints between them and leads to increased air permeability barriers, and under the influence of dynamic loads - also to the damage of joints, that significantly reduces the service life of the rig.

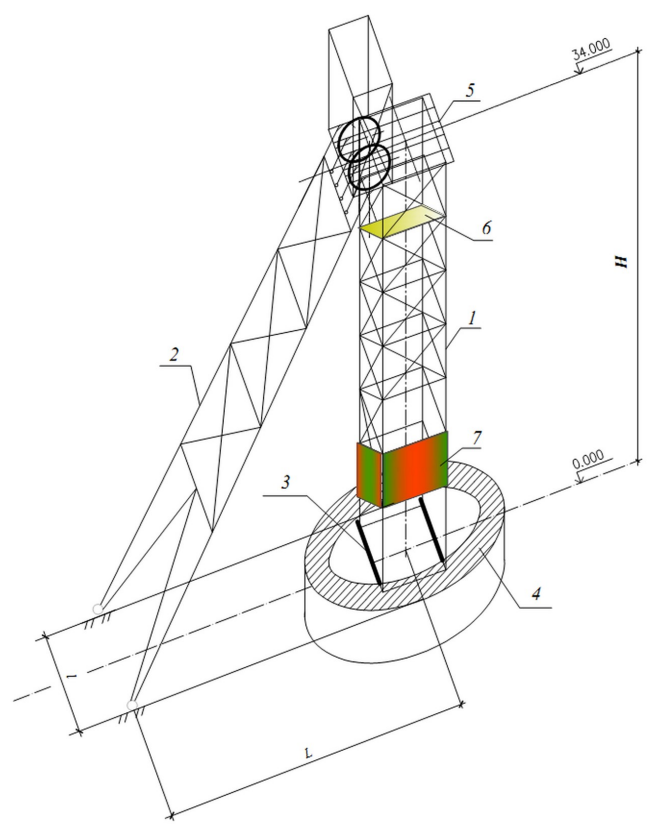

Fig. 1. Schematic of Steel Four-Post Headframe of Rig System: 1 - rig; 2 - jib; 3 - support frame; 4 mine mouth; 5 - pulley pad; 6 - shock absorbers pad; 7 - lining. 
In addition, rectangular rig configuration is connected with a possibility of conveyance dumping in two directions only: in the lifting plane and from the lifting plane.

Attempts to eliminate these disadvantages have been taken by M.M. Zerbinin in headframe of cylindrical system used in the mines of Donbass during the postwar years [12]. The main drawback of this headframe is support of cylinder on the mine mouth, which should take significant bending moments from lifting, which greatly complicates the design of headframe and mine mouth.

The Department of Underground Facilities and Mines Construction at KuzSTU developed a constructive solution for the headframe of multifunctional purpose $[15,16$, 11]. The developed design made it possible to eliminate disadvantages of cylindrical headframe in parts of the upper and lower support units and preserve all its advantages.

The headframe (Fig. 3) consists of sheave wheels (it includes frame jib 1 of variable box cross-section, central tubular post 2, pulley pads 3 and 4, the annular spacer 5) and rig of circular cross-section 6 , supported on mine mouth 7 via walling curb 8 . follows:

The presented design of multifunctional headframe solves the design problems as 1) loads from lift works are taken by independent block - sheave wheels $1-5$, and not transmitted to mine mouth 7;

2) loads from guide conveyances 9 are taken by frameless round rig 6 , and transmitted to mine mouth via walling curb 8 ;

3) compression and depression loads are taken by ring elements 10 (see Fig. 3) of rig.

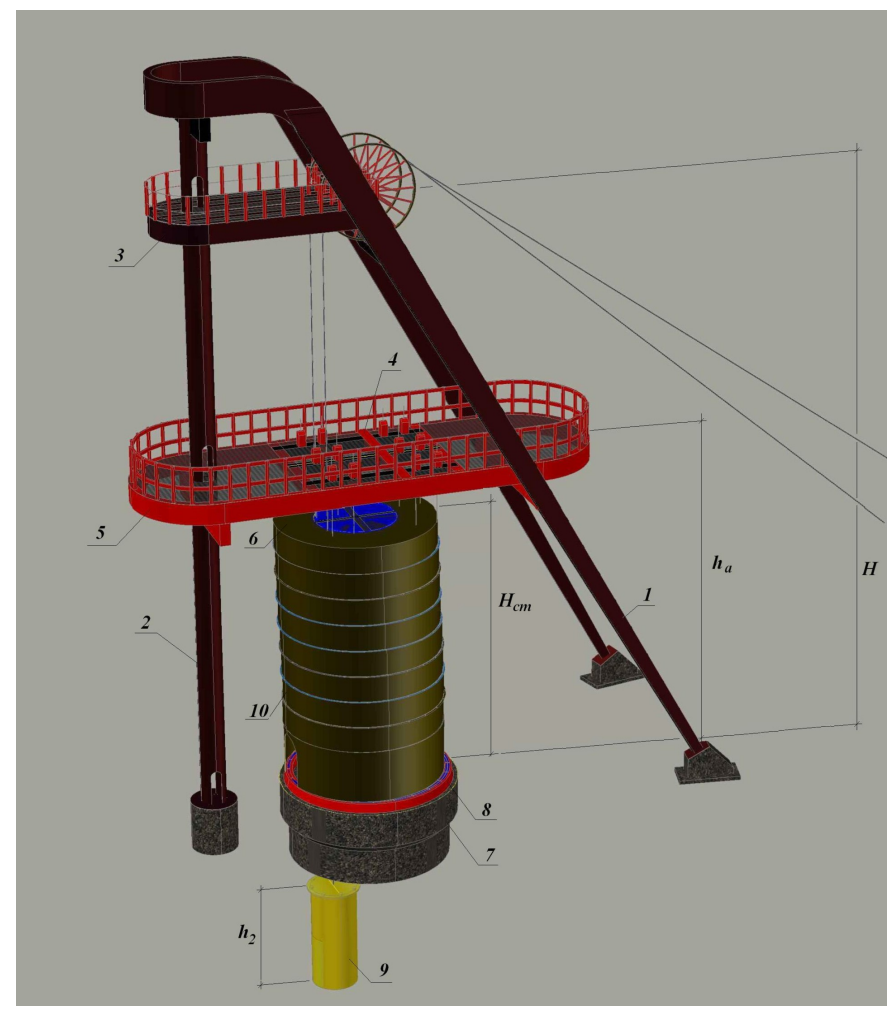

Fig. 2. Schematic of steel headframe of multifunctional purpose for operational time: $1-\mathrm{jib} ; 2-$ central tubular post; 3, 4 - pulley pads; 5 - ring base; 6 - rig; 7 - mine mouth; 8 - walling curb; 9 conveyance; 10 - ring element. 


\section{Results}

The offered technical solution is protected by patents of the Russian Federation [10-12] and has the following advantages versus cylindrical headframe and rig type headframe:

- frameless round rig [11] is separated from the sheave wheels, does not perceive and transmit load from pulleys to mine mouth, that greatly simplifies support unit on mine mouth;

- absence of base frame simplifies rigging up process of rig, makes operating conditions easier;

- absence of braces on frame jib and rig provides easy access for inspection and protection of elements and structure units, as well as it eliminates accumulation of coal dust, slag and lube at the nodes of connection;

- frameless rig 6 (see Fig. 3) consists of ring elements 10, which have a much smaller number of joints and more reliable sealing versus to frame rigs 1 (see Fig. 1) with traditional fencing panels;

- ring elements have high resistance to bending and torsion, are more resistant to action of dynamic and wind loads;

- round cross-section on cut-away view of the frameless rig meets the layout requirements with some reserve in areas and volumes, which ensures the maximum possible equipment location;

- dumping of conveyances is possible in any direction, as openings in circular rig has no restrictions.

The main disadvantage of the headframes of multifunctional purpose is the lack of school for their design. If the designing of the rig headframes is based on the verified methods applying the vast domestic experience, then there is no technology for designing of the proposed headframe system.

Design of a headframe of any system starts with the determination of the headframe height $H$.

Determining the rig headframe height $H$, it is assumed that the height of the rig and the height of the headframe are identical concepts, and are measured as the difference between the marks of the axis of the upper head-block and mine mouth [12].

In case of placement of the head block on the same level:

$$
H=h_{1}+h_{2}+h_{3}+0.75 R_{s c \kappa},
$$

where $h_{1}$ - dumping place height, $\mathrm{m} ; h_{2}$ - conveyance height, i.e. distance from the dumping place to upper wire rope clip of suspension gear, $\mathrm{m} ; h_{3}$ - overwind height, $\mathrm{m} ; R_{s c \mathrm{~K}}$ - head block radius, $m$.

Based on this, possible removal of winding machine from shaft $\boldsymbol{l}$ is accepted, that often causes difficulties in the already existing layout of the mine surface.

In angle headframes of multifunctional purpose the headframe height $H$ and the rig height $H_{c m}$ are different parameters. The rig height is calculated as per the formula as follows:

$$
H_{c m}=h_{a}-2 \mathrm{~m}
$$

where $h_{a}$ - height of the sinking sheave wheels pad as per technological requirements, $\mathrm{m}$;

The headframe height $H$ means the sheave wheels height 1-5(see Fig. 2). In this case, removal of winding machine from shaft $l$ is assigned by a customer, based on specific conditions of the mine surface layout, and the headframe height $H$ is determined by computation chart (Fig. 4).

Analysis of the acting Federal regulations and rules in terms of industrial safety, as well as a priori sources $[2,3,4]$ has shown that the allowed value area (AVA) $H \geq H_{i}^{\text {min }}$ (Fig. 3) 
of the headframe of multifunctional purpose is determined based on the following conditions:

a) maximum angle of inclination of the rope string to the horizon $\beta_{1}=50^{\circ}$;

b) minimum angle of inclination of the rope string to the horizon $\beta_{2}=30^{\circ}$;

c) maximum permissible length of the rope string $L_{\beta}{ }^{\max } \leq 65 \mathrm{~m}$;

d) compliance with the maximum deviation angles $\alpha_{\mathrm{dev}} \leq 1^{\circ} 30^{\prime}$;

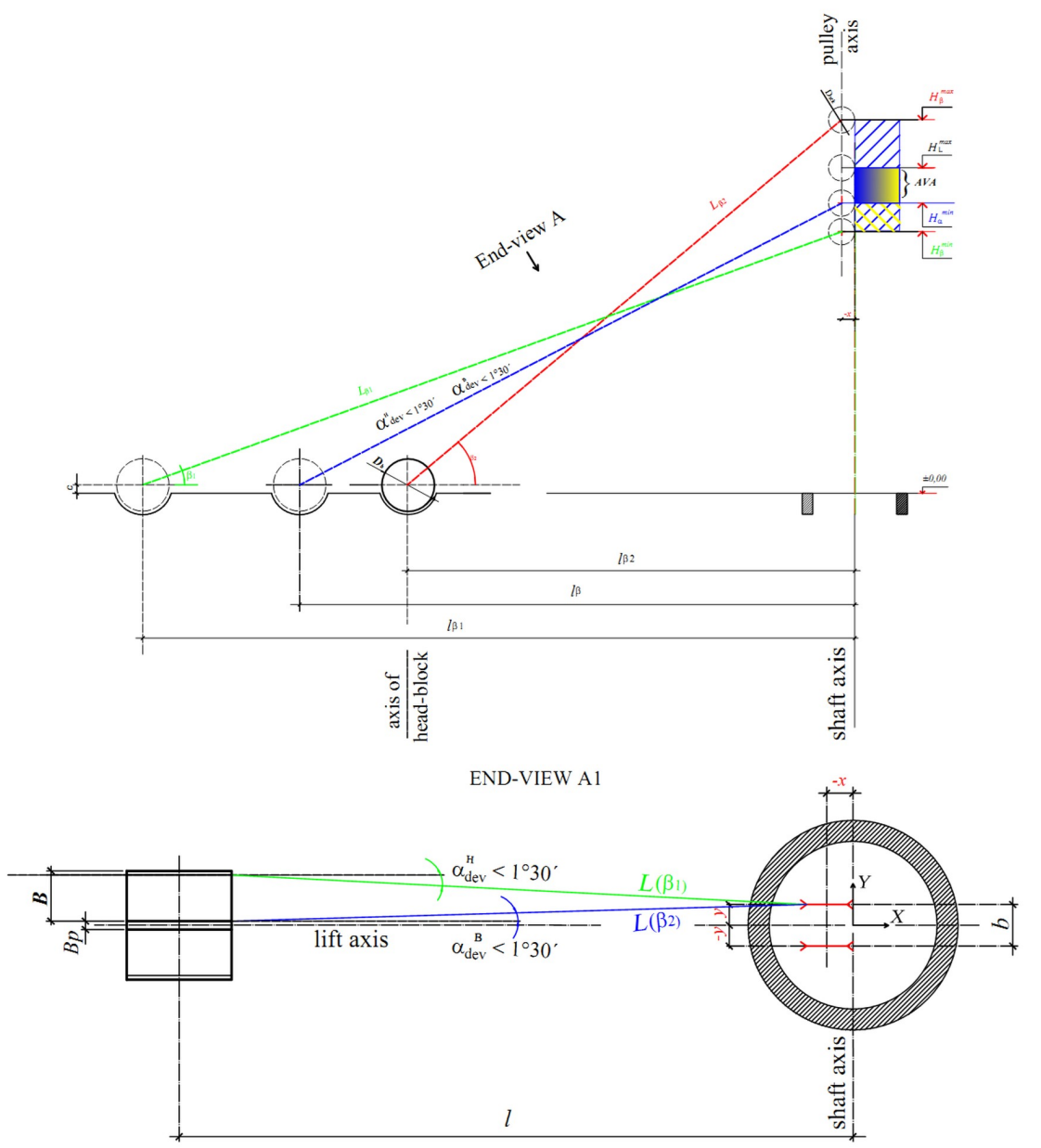

Fig. 3. Scheme to determine the allowed value area (AVA) of the sheave wheels height $H$ depending on the critical deviation angles $\alpha_{\mathrm{dev}}^{\mathrm{H}}, \alpha_{\mathrm{dev}}^{\mathrm{B}}$ on critical angles of the rope string inclination to the horizon $\beta_{1}, \beta_{2},{ }^{\circ}$ on critical rope string length $L_{\beta}$

The obtained values of $H\left(H_{\alpha i}{ }^{\max }, H_{\beta i}{ }^{\min }, H_{\beta i}{ }^{\max }, H_{L}{ }^{\max }\right)$ are calculated as dependences on distance $l$, which in turn has boundary conditions [10-12]:

- maximum possible closing of the winding machine base and jib base as per the YUZHGIPROSHAKHT formula:

$$
l_{\text {min }}^{\prime}=0,45 H+D_{b}+0,5 D_{s c k}+6 \text {; }
$$

- maximum possible closing of winding machine and headframe to eliminate vibration from headframe to winding machine 


$$
l^{\prime \prime}{ }_{\min }=0,6 H+D_{b}+3,5 \mathrm{M}
$$

- maximum possible removal of winding machine from headframe, guaranteeing absence of vibration of the inclined part of the hoisting line without installing additional support pulleys

$$
l_{\max }=1,4(H-\mathrm{c})+0,5 D_{\text {sck }}
$$

Taking into account these conditions, the boundary conditions are computed for $H$ (Hl'min, $H l^{\prime \prime}$ min, Hlmax) on $l$.

Meanwhile it is required to consider the boundary conditions for $H$ as per technological requirements:

$$
H t \geq h_{a}{ }^{\min }+3 \mathrm{M}
$$

where $h_{a}{ }^{\text {min }}=19 \mathrm{~m}-$ minimum height of the sinking sheave wheels pad as per technological requirements, $\mathrm{m}$.

Based on the conducted factor analysis and as a result of numerical experiments the allowed value area (AVA) of the headframe heights $H$ (see Fig. 4) has been determined.

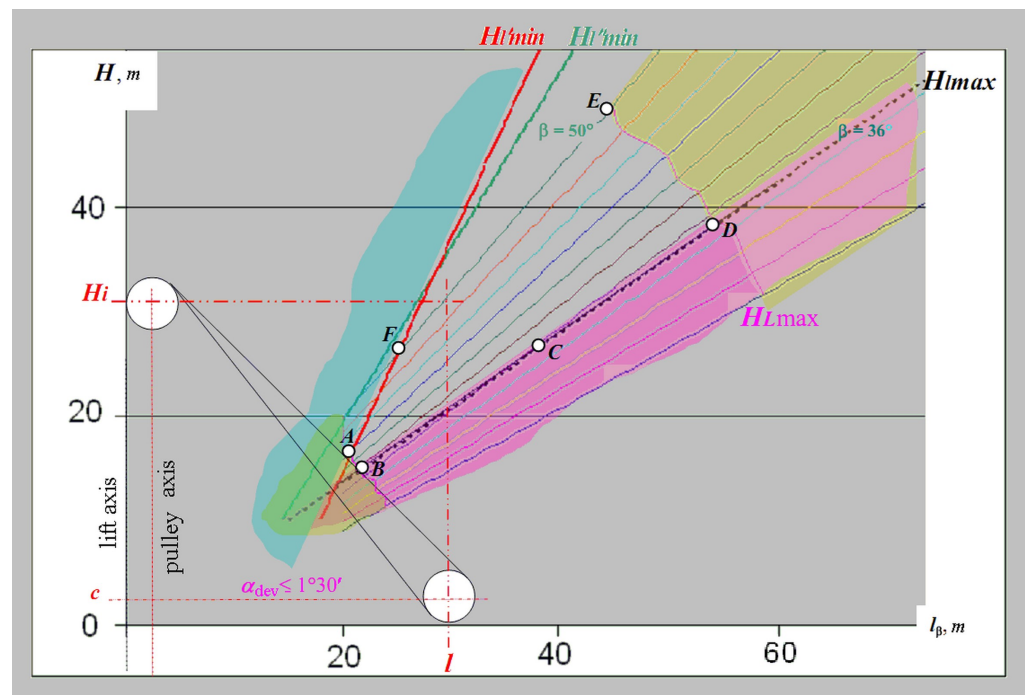

Fig. 4. Computation chart for the AVA graphical determination of the headframes heights $H$ at the wheel width $B=3 \mathrm{~m}, b=1.45 \mathrm{~m}, D_{s c k}=5 \mathrm{~m}, D_{b}=5 \mathrm{~m}$. The coordinates of the AVA boundary points: $A(21,15 ; 7), B(22,1 ; 15), C(33.0 ; 22.82), D(55.0 ; 38.5), E(45.0 ; 49.65), F(25.45 ; 26.50)$.

The obtained computation chart allows determining the headframe height $\boldsymbol{H}$, depending on the winding machine type and layout $\boldsymbol{l}$ relatively to the shaft, based on the specific conditions of the mine surface layout.

\section{Conclusion}

The proposed idea of independently operating structural units, one of which is a round rig, significantly reduces the number of controlled variables with which a designer can vary while the headframe designing. This greatly simplifies automation of the design process in search of an optimal solution, not a typical one, but an individual one.

This approach allows us to formalize the search for optimal technical solutions in lieu of the optional design and formulate a new design concept for steel angle headframes for state-of-art. 


\section{References}

1. D. W. Butler, A. C. Schneyderberg, Mining Congress Journal, 7:1, 15 (1982)

2. F. A. Edwards, Society for Mining, Metallurgy, and Exploration, 2, 125 (1992)

3. J. I. Rojas-Sola, J. M. Montalvo-Gil, M. Castro-Garcia, 181, 118 (2013)

4. H. L. Hartman, S. G. Britton, J. M. Mutmansky, Society for Mining, Metallurgy, and Exploration, 3, 342 (1998)

5. I. Ross, Goldcorp going electric with Chapleau gold mine (Northern Ontario Business, Ontario, 2016)

6. J. I. Rojas-Sola, I. Palomares-Muñoz, Dyna, 6, 602, (2015)

7. F. Wei, I. F Wang, R. 3D Parametric Design for Steel Headframe of Coal Mine Based on Solidworks (Key Engineering Materials, London, 2010)

8. L. Kelly, Histor. End., 34, 31 (2014)

9. E. U. Reuther, Erster Band, 12, 37 (2010)

10. E. G. Kassikhina, Gornyi zhurnal, 8, 56 (2017)

11. E. G. Kassikhina, Qiao Weiguo, V. V. Pershin, N. O. Butrim, Selection of a Rational Form for the Steel Winding Tower as a Preventive Measure to Increase its Industrial Safety (Atlantis Press, Paris, 2014)

12. E. G. Kassikhina, V. V. Pershin, J. F. Glazkov, E3S Web Conf., 41, 01025 (2017) 